\title{
Microscopic and Molecular Diagnosis of Theileria annulata and Their Control in Cross-bred Cattle in Southern Region of Chhattisgarh
}

\author{
K. R. Baghel*, S. Bisen, S. Nety and M. R. Poyam \\ Department of Veterinary Parasitology, College of Veterinary Sciences and Animal \\ Husbandry, Anjora-Durg, (Chhattisgarh), India \\ *Corresponding author
}

\section{A B S T R A C T}

Keywords

Bovine tropical theileriosis,

Theileria,

haemoprotozoa,

Buparvaquone

Article Info

Accepted:

12 December 2020

Available Online:

10 January 2021
An outbreak of bovine tropical theileriosis was controlled in a cattle farm maintained at Jin Kaushal gosala Jagdalpur, District Bastar, Chhattisgarh. Out of 70 indigenous (30) and cross-bred animals (40), 7 exhibited symptoms of pale mucous membrane, swollen pre-scapular lymph node and temperature $103^{\circ} \mathrm{F}$ $106^{\circ} \mathrm{F}$. Symptomatic treatment was given with Oxytetracycline and Dexamethasone, Meloxicam along with supportive therapy but 3 animals were found dead, despite treatment. Following detection of Koch blue bodies (schizonts) and piroplasm in blood smear and molecular diagnosis using cytob1 gene of $T$. annulata, rest clinically infected animals were cured treating with Buparvaquone at single recommended dose $(2.5 \mathrm{mg} / \mathrm{kg}$.b.wt. i.m). Postmortem examination of dead animals revealed pathognomonic lesions punched out ulcers in the mucous membrane of abomasum.

\section{Introduction}

Bovine tropical theileriosis is an important tick borne disease of bovine responsible for heavy economic losses to the dairy industry. The disease is caused by Theileria annulata, an intracellular apicomplexan haemoprotozoa and is mostly prevalent in tropical and subtropical regions of the world including India (Uilenberg, 1981). The outcome of the disease is highly fatal in exotic and crossbreds of all age group of cattle and high mortality and heavy productive losses have been reported from different parts of the country
(Jitendran, 1997; Kohli et al., 2014; Kolte et al., 2017). In India, 39 million cross-bred cattle are at risk of $T$. annulata infection (Kolte et al., 2017). Clinically infected animal is mainly diagnosed by clinical symptoms and microscopic observation of piroplasm infected RBCs and schizonts infected lymphocytes in Giemsa stained thin blood and lymph node smear, respectively (OIE, 2014; Tuli et al., 2015) where as serological (IFAT, ELISA) and molecular methods (PCR) are employed to diagnose sub-clinical form of theileriosis. Proper management of tick infestation and treatment of infected animals 
using effective drugs are essential for the control the theileriosis. The present study reports a microscopic and molecular diagnosis, pathognomonic lesions and control of bovine tropical theileriosis in cross-bred cattle in southern region of Chhattisgarh.

\section{Materials and Methods}

Out of 70 cattle of indigenous (30) and HF cross-bred (40) maintained at Jin Kaushal gosala, Jagdalpur, District Bastar, Chhattisgarh, 7 female cross-bred, 4-5 years age, were reported with the history of anorexia, dullness and decline of milk yield from 10 days. Clinical symptoms predominantly observed were pale mucous membrane, swollen pre-scapular lymph node and high rectal temperature $\left(103^{\circ} \mathrm{F}-106^{\circ} \mathrm{F}\right)$. Despite treatment, three affected animals succumb to death and post-mortem was conducted to observe the lesions. Blood was collected aseptically from jugular vein of rest of the animals in sterile vial containing 1\% EDTA. Thin blood smear was fixed with methanol and stained with Giemsa stain.

\section{DNA isolation and molecular confirmation}

Genomic DNA was extracted from $200 \mu 1$ of the whole blood using DNA extraction kit (DNeasy blood kit, Qiagen) as described by manufacturer's protocols. The PCR was carried out in a reaction volume of $25 \mu \mathrm{l}$, consisted of $8.5 \mu \mathrm{l}$ nuclease free water, dream taq master mix $12.5 \mu 1$, cyto b1 primers ( $\mathrm{F} \&$ R) $1 \mu \mathrm{l}$ each, template DNA $2 \mu \mathrm{l}$ and $2 \mu \mathrm{l}$ NFW was used in negative control. Primers used were specific to cytob1 gene of $T$. annulata under the following cycling conditions as described by Bilgic et al., (2013): an initial denaturation at $94^{\circ} \mathrm{C}$ for 3 min followed by 30 cycles of denaturation $\left(95^{\circ} \mathrm{C}\right.$ for $\left.50 \mathrm{~s}\right)$, primer annealing $\left(50^{\circ} \mathrm{C}\right.$ for $50 \mathrm{~s}$ ) and extension $\left(65^{\circ} \mathrm{C}\right.$ for $\left.1 \mathrm{~min}\right)$ and final extension at $65^{\circ} \mathrm{C}$ for $10 \mathrm{~min}$ was performed. Amplified product was resolved in $1.4 \%$ agarose gel electrophoresis and image was captured in a gel documentation system.

\section{Results and Discussion}

Microscopic examination of Giemsa stained thin blood smear under oil immersion revealed schizont infected mononuclear cells (Koch blue bodies) and piroplasm infected RBCs. The K.B.B. observed were 5-6 small rounds, bluish-purple stained bodies in lymphocyte (Fig.1) and parasitized RBCs with ring shaped piroplasms in Giemsa stained smear (Fig.2). The percentage of parasitaemia was $30 \%-50 \%$. Animals with less than $30 \%$ parasitaemia, were managed to cure successfully while three animals with $50 \%$ parasitaemia were succumb to death despite treatment. The collected ticks were identified as Hyalomma anatolicum, the vector of T. annulata (Soulsby, 1982).

Genomic DNA amplified using T. annulata specific cytob1 gene primers was analyzed by running $10 \mu 1$ of PCR amplicon in $1.4 \%$ agarose gel electrophoresis containing 10 $\mu \mathrm{g} / \mathrm{ml}$ ethidium bromide in Tris-acetateEDTA (TAE) buffer at $50 \mathrm{~V}$ for $1 \mathrm{~h}$ and specific $312 \mathrm{bp}$ product size was visualized under UV light and image was captured in a gel documentation system.

The postmortem examinations were carried out to find out specific lesions linked to $T$. annulata infection. The most common lesions observed were enlarged superficial lymph nodes and spleen, liver and pulmonary emphysema, excessive pericardial and pleural fluid, subcutaneous and intramuscular hemorrhages. Many haemorrhagic and multifocal circular depressed necrotic ulcers were detected in mucous membrane of abomasum (Fig.4). These are punched out ulcers, specific lesions pathognomonic to bovine tropical theileriosis (Soulsby, 1982). 
Fig.1 Koch blue bodies in lymphocyte

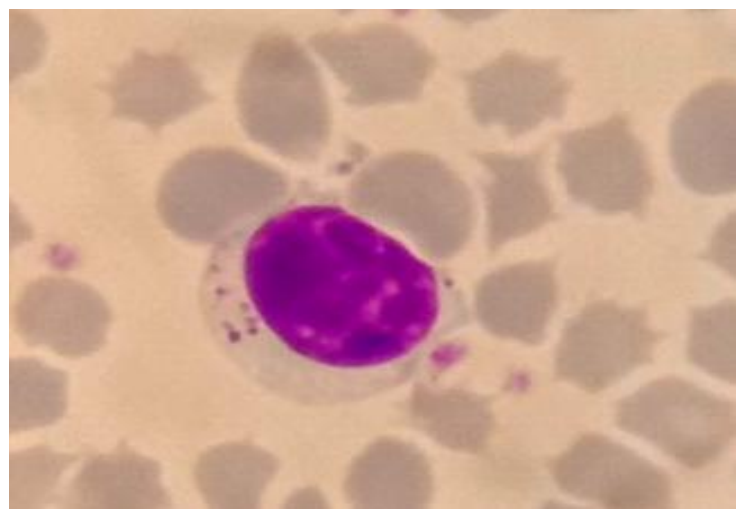

Fig.2 Parasitized RBCs with piroplasms

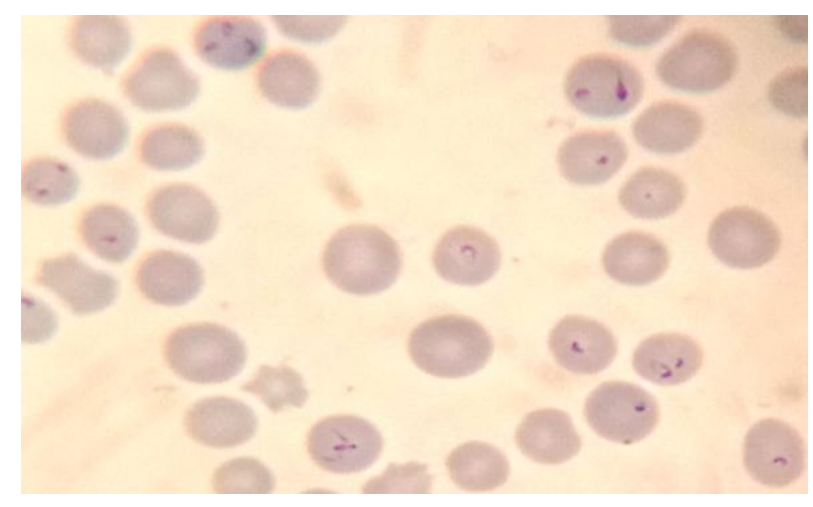

Fig.3 Molecular detection of T. annulata (Lane M: 100bp DNA ladder; lane 1: Amplicon of 312 bp size; lane 2: negative control

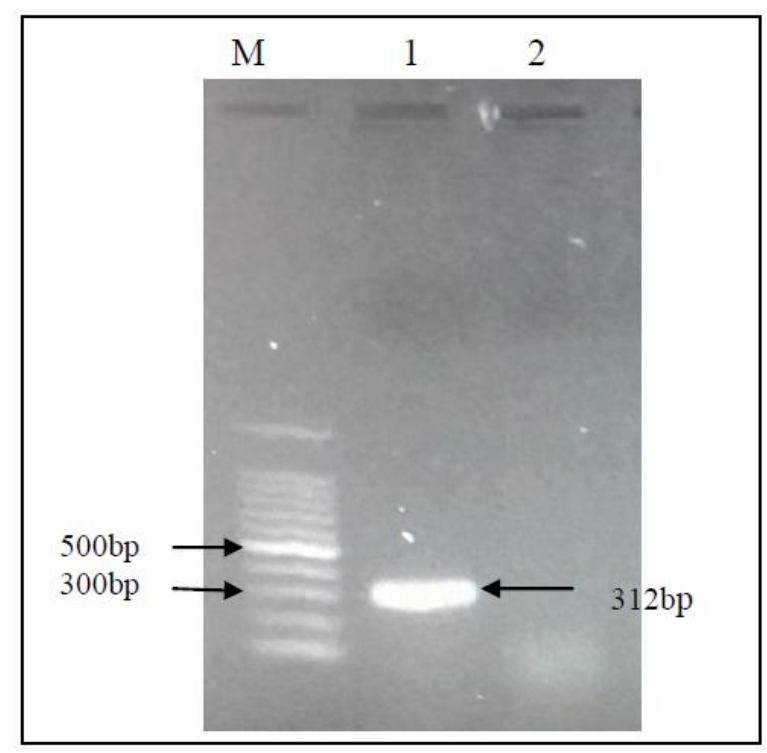


Fig.4 Punched out ulcer in abomasum

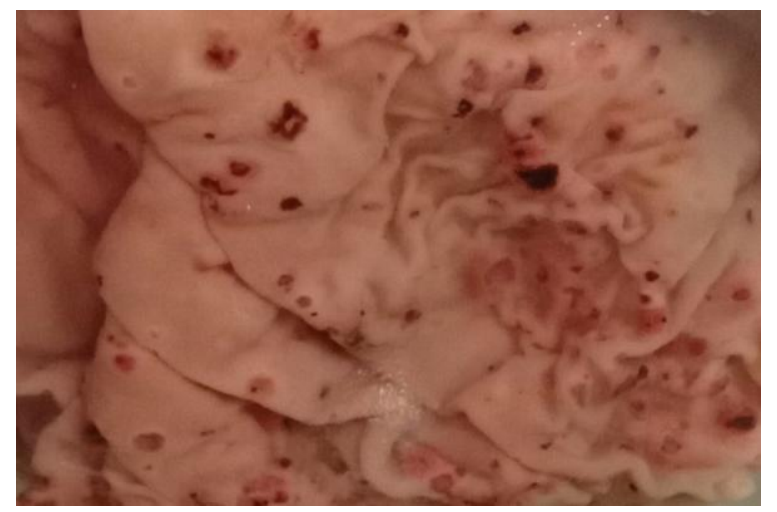

All the clinically affected animals were treated with Oxytetracycline (OTC) @ 10 mg/kg.bwt. i.m., Dexamethasone $4 \mathrm{ml}$ s/c, meloxicam $10 \mathrm{ml} \mathrm{i} / \mathrm{m}$ for 3 days along with $5 \%$ dextrose as supportive therapy but three animals did not respond to treatment and succumb to death. Remaining 4 animals were cured treating with single dose of Buparvaquone (Butalex) @ 2.5mg/kg.bwt i/m, after confirmation of $T$. annulata with microscopic examination. Improvement on the health of animals was recorded after $3^{\text {rd }}$ day post treatment. Buparvaquone is a promising therapeutic compound act on both schizont and piroplasm stages where as Oxytetracycline inhibit initial establishment of schizonts and their ability to transform host cell, therefore OTC is ineffective when used therapeutically during patent phase (Spooner, 1990). Dexamethasone (Glucocorticoides) maintains the vascular integrity and antagonizes the effect of chemical mediator of inflammation, thereby prevents the formation of pulmonary oedema in theileriosis (Gwamaka et al., 2004). Many authors reported successful treatment of this disease using Buparvaquone along with other supportive drugs Dexamethasone and Meloxicam (Gwamaka et al., 2004; Gupta et al., 2004; Verma and Singh, 2016). Special attention is required for management of exotic and cross-bred dairy animals, as they are highly susceptible to $T$. annulata infection due to genetic makeup and weakening of immunity due to stress in summer season and also proper management of vector in endemic region to control the outbreaks.

\section{References}

Bilgic, H. B., Karagenc, T., Simuunza, M., Shiels, B., Tait, A., Eren, H. and Weir. W. (2013). Development of a multiplex PCR assay for simultaneous detection of Theileria annulata, Babesia bovis and Anaplasma marginale in cattle. Experimental Parasitology, 133: 222229.

Gupta, S.K., Yadav A, Raina, A.K. and Singh, R. (2004). Theileriosis in a seven-day old bovine calf - a case report. Indain Journal of Veterinary Medicine, 24: 55.

Gwamaka, M., Matovelo, J. A., Mtambo, M.M.A., Mbassa, G. K., Maselle, R. M. and Boniphace, S. (2004). The effect of dexamethasone and promethazine in combination with buparvaquone in the management of East Coast fever. Onderstepoort Journal of Veterinary Research, 71:119-128.

Jithendran, K. P. (1997). Blood protista of cattle and buffaloes in Kangra valley, Himachal Pradesh. Indian Journal of Animal Sciences, 67: 207-208.

Kohli, S., Atheya, U. K. and Thapliyal, A. 
(2014). Prevalence of theileriosis in cross-bred cattle: its detection through blood smear examination and polymerase chain reaction in Dehradun district, Uttarakhand, India. Veterinary World, 7: 168-171.

Kolte, S.W., Larcombe, S.D., Jadhao, S. G., Magar, S.P., Warthi, G. and Kurkure, N.V. (2017). PCR diagnosis of tickborne pathogens in Maharashtra state, India indicates fitness cost associated with carrier infections is greater for crossbreed than native cattle breeds. PLoS ONE 12: e0174595. https://doi.org/10.1371/journal.pone.017 4595

OIE, (2014). Manual of Diagnostic Tests and Vaccines for Terrestrial Animals, vol. 1-2, seventh ed. Office International Des Epizooties, Paris.

Soulsby, E. J. L. (1982) Helminth, Arthropods and Protozoa of Domesticated Animals. $7^{\text {th }}$ ed. Billiere Tindal, Londan. pp. 733 -
735.

Spooner, P. R. (1990). The effects of oxytetracycline on Theileria parva in vitro. Parasitology, 100: 11-17.

Tuli, A., Singla, L.D., Sharma, A., Bal, M.S., Filia, G. and Kaur, P. (2015). Molecular epidemiology, risk factors and hematochemical alterations induced by Theileria annulata in bovines of Punjab (India). Acta Parasitology, 60: 378-390.

Uilenberg, G. (1981). Theilerial species of domestic livestock. In: Irving, A.D., Cunningham, M.P., Young, A.S. (Eds.), Advances in the Control of Theileriosis. Martinus Nijhoff Publishers, The Hague, Boston, London, pp. 4-37.

Verma, A. K. and Singh, S. K. (2016). Control and therapeutic management of bovine tropical theileriosis in crossbred cattle. Journal of Parasitic Disease, 40(1):208-210.

\section{How to cite this article:}

Baghel, K. R., S. Bisen, S. Nety and Poyam, M. R. 2021. Microscopic and Molecular Diagnosis of Theileria annulata and Their Control in Cross-bred Cattle in Southern Region of Chhattisgarh. Int.J.Curr.Microbiol.App.Sci. 10(01): 975-979. doi: https://doi.org/10.20546/ijcmas.2021.1001.118 